\title{
Erratum to: Bilateral pneumothorax in pregnancy unmasking lymphangioleiomyomatosis
}

\author{
C. R. Johnston • M. E. O'Donnell • W. A. Sayed Ahmed • \\ A. Hunter · A. N. Graham
}

Published online: 9 April 2014

(C) Royal Academy of Medicine in Ireland 2014

Erratum to: Ir J Med Sci (2011) 180:933-934

DOI 10.1007/s11845-010-0628-6

The name of the author W. A. Sayed Ahmed was rendered incorrectly in this article.

The online version of the original article can be found under doi:10.1007/s11845-010-0628-6.

C. R. Johnston $(\varangle)$ · A. N. Graham

Department of Thoracic Surgery, Royal Victoria Hospital, Grosvenor Road, Belfast BT12 6BA, Northern Ireland, UK

e-mail: ruthjohnston@ doctors.org.uk

C. R. Johnston

18 Lewis Drive, Belfast BT4 1EN, Northern Ireland, UK

M. E. O’Donnell

Department of General Surgery, Royal Victoria Hospital,

Grosvenor Road, Belfast BT12 6BA, Northern Ireland, UK

M. E. O’Donnell

Faculty of Life and Health Sciences, University of Ulster,

Belfast, Northern Ireland, UK

W. A. Sayed Ahmed · A. Hunter

Department of Obstetrics, Royal Victoria Hospital,

Grosvenor Road, Belfast BT12 6BA, Northern Ireland, UK 